\title{
On Differences between Eastern and Western Plastic Arts
}

\author{
Lu Xue \\ College of Art and Appareluages, Tianjin Polytechnic University, Tianjin 300384, China \\ E-mail:lianglu1125@126.com
}

\begin{abstract}
Plastic arts refer to the creation of visual static images with some substantial materials as well as methods, including architecture, sculpture, painting, industrial arts, design, calligraphy and seal cutting and so on. Due to the differences between the eastern and western cultures, plastic arts also display different characteristics. To be more specific, different geographical environments and social and historical environments have led to different cultural foundations of the two. The Chinese culture emphasizes the kinship while the western culture puts more importance to individual equality; the Chinese culture emphasizes ethical rules while the western culture the exploration into objective rules; the Chinese culture emphasizes harmony while the western culture opposition, hence resulting in the differences in Chinese and western value orientations. In addition, in the comparison between Chinese and western philosophy, the former seems to be macroscopic and comprehensive with its emphasis on the harmony between opposite sides and the inner experiences while the latter tends to be more scientific due to its division between sensibility and reason, individuality and generality.
\end{abstract}

Keywords: Plastic arts, Difference Analysis, Cultural foundation, Value orientation, Difference in philosophy

Plastic arts refer to the creation of visual static images with some substantial materials and methods, including architecture, sculpture, painting, industrial arts, design, calligraphy and seal cutting and so on. They have displayed different trends and characteristics in the east and the west.

Some well-known ideas on plastic arts in China are given as follows:

During the Spring and Autumn and the Warring States Periods, painting's advantage in remaining images was mentioned in some ideologists' works.

A famous painter in East Jin Dynasty, Gu Kaizhi, emphasized the importance of "the convey of spirit", changing the longlasting traditional ideas to purely pursue similarities in shape. In this way, a new foundation is provided for us to understand the characteristics of painting arts.

In Song Dynasty, the "expression of feelings" theory came into existence, maintaining that paintings should be relied to express the painter's feelings. According to this theory, similarities in shape would give way to expression of feelings although they shouldn't be neglected totally.

Wang Bo in Ming Dynasty gave a more profound and dialectic explanation about the similarities in shape, which is regarded to step further towards the characteristics of painting.

It was revealed in Bai Juyi's description of Zhang Zao's painting course that painters are good at combining their subjective experiences with the objective environment and then forming images in their minds. Accepting this theory, a contemporary painter, Pan Tianshou maintains that although the images come form the objective world, they are different from the real ones due to the painters' subjective experiences.

Su Shi in Northern Song Dynasty proposed the theory of "to have a well-thought-out plan", according to which painters are expected to form mature and complete images in their minds before reconstructing them on paper. This theory has been accepted by the following painters as a basic principle. In Qing dynasty, Zheng Banqiao proposed another theory- "the bamboo outside mind" as a supplement for Su Shi's. In addition, Zheng Banqiao also pointed out the differences among "the bamboo in mind", "the bamboo in eyes" and "the bamboo in hand", hence giving a more vivid explanation for the painting course.

Meantime, Wang Bo's theory has been accepted by a lot of painters in modern China, such as Shi Tao, Qi Baishi and Huang Hongbin. According to Qi Baishi, the intermediate state between similarity and non-similarity is the excellent one because "paintings which are similar to something too much seem meretricious while ones which are not seem deceptive". Huang Hongbin maintains that real similarities should come from those with some changes.

And the following are some famous theories on plastic arts in the west:

Duing Revival of Learning, Italian painter Leonardo Da Vinci thought that painting, as a science branch, begins with points, 
and then extends to lines, sides and comes to shapes. Besides, according to him, the proper use of shadows will help to create a concavo-convex effect. In addition, color, shape and distance of objects in painting, as well as the mistiness of objects caused by distance are also included in painting science, which is regarded as the origin of perspective study.

According to German classical philosopher Hegel, the principle nature of a subject matter, instead of the subject matter itself, has taken a more and more significant role in painting. In one of his important works- Aesthetics, it is pointed out that the subject matters for painting mainly come from those things which can be manifested from the externality. In his opinion, the inner world will not be reflected by the external images directly in painting. Instead, movement will be employed to uncover the hidden inner world.

French classicalism painter Angel maintained that the emotional expression of painting is closely related to plastic arts and therefore the latter is expected to search for and accumulate natural beauty. French Romanticism painter Eugene Delacroix emphasized the importance to express the painter's fantasies and impressions. While another painter Gustave Courbet believed that painting, as a concrete artistic form, is expected to manifest those visible and existing things and therefore, a faithful reproduction should be given in painting.

In Pissarro's theory, painting is employed to reveal feelings, so it shouldn't be restricted by rules or principles. While according to the postimpressionist school, volume, color and the spirit of painters should get emphasized in painting. Cézanne claimed that sculpt should go along with the natural things instead of pursuing them.

According to Henri Matisse, a representative of fauvism, painting is mainly to manifest things with its concern about the shape of objects. In his opinion, cube and globe is the only necessary things for painters. While for Picasso, not only what is seen but what we think about things should be manifested in painting.

The following conclusions can be reached from the above thoughts: Influenced by the western scientific ideology and the eastern sensational ideology, plastic arts display different characteristics between the two. Just as what Li Dazhao, one of the founders of CCP, has said in Basic Differences Between the Eastern and Western Civilizations, there are some major differences between the two: one pursues quiescence while the other movement; one pursues natural things while the other artificial ones; one desires for peace while the other for war; one is negative while the other positive; one is dependent while the other independent; one prefers coziness while the other initiative; one would like to follow while the other to create; one tends to be conservative while the other would like to try on different things; one pursues arts while the other science; one emphasizes spirit while the other substance; one emphasizes human soul while the other flesh; one believes in nature's control over man while the other maintains that man can conquer nature. Accordingly, these above differences should be traced back to the general differences between the eastern and western cultures with the following reasons:

(1) A Comparison in Cultural Foundation

Generally speaking, differences in culture lie in different production modes and life styles caused by different geographical environments.

Different geographical environments:

China has as large an area as whole Europe does. The surrounding mountains and oceans set barriers between this nation and the outside world as well as providing large space for their people, hence resulting in China's self-sufficient agricultural economy. Until our human society stepped into the capitalist industrial stage did the Chinese agricultural civilization stay among the top of the world.

The ancient Europeans used to live along the southwestern coastline, hence forming animal husbandry as their main production mode. In addition, their constant migrations resulting from the small amount of land fit for farming increased the clash and amalgamation with other nations and therefore, gave profound influences to their culture. Furthermore, their convenient waterway transportation has also provided favorable conditions for their business development in the ancient and modern times.

Different social and historical environments:

Differences in geographical environment have led to those in production, and then to those in social and historical conditions. As an internal condition for culture, social and historical environment has played a decisive role in the formation of culture.

The historical characteristics of the ancient Chinese society can be summed up as follows:

First of all, self-sufficient agricultural economy was the economic basis of the ancient Chinese society. Due to its advantage in producing more in a certain amount of land, it had provided substantial conditions for the patriarchal clan system in ancient China. Accordingly, with the royal authority as its center, the ancient Chinese society was composed of individual families which were formed according to kinship.

Different from ancient China, the ancient European society has the following characteristics:

First, ancient Europe had advanced industry and commerce as well as agriculture and animal husbandry. By the end of the Middle Ages, its coastal business economy had reached a quite high level, and what's more, stock exchange began to 
appear in $14^{\text {th }}$ to $15^{\text {th }}$ century.

Second, it had a social structure based on feudal manor economy, connected by laws and centered on thearchy. The traditional western social structure was based on its agricultural civilization and the industrial and commercial one. With manor economy as its base, the feudal hierarchical system was formed with the relationship between landlords and homagers according to their contracts and therefore the divided administrative and judicial authority.

(2) A Comparison in Value Orientation

The differences between eastern and western value orientations are mainly shown in the following aspects:

Kinship in Chinese culture \& individual equality in western culture:

Due to the patriarchal clan system in Chinese society, kinship seems to be particularly important for Chinese people.

Compared with the Chinese society, the western society has put less importance on kinship due to the development of commercial civilization in ancient Greece. Instead, equal status and free decision rights as required in commercial exchange have promoted the formation and development of people's ideas in equality and freedom. Particularly in the modern times, the capitalist class proposes equality and freedom as its banners.

Ethics in Chinese culture \& objective laws in western culture:

The structure of the Chinese society makes it important to think a lot about personal relationship and steady social orders. In ancient China, ethics and morality took a quite important position in Chinese culture.

It is different in western culture. As early as in ancient Greece, people began to explore the world from the perspective of nature instead of only personal relationship. They divided the whole world into man and nature, hence trying to find out reasons and sources from the objective world.

Harmony in Chinese culture \& opposition in western culture:

It is also due to kinship in Chinese society that Chinese people follow the principle of "harmony" when dealing with all kinds of relationships. If family members don't get along well with each other, the whole family will run the risk of splitting up. Just like Confucius once said, politeness should be employed to keep harmonious relationship between each other. When it comes to arts, the unity between sentiment and scene is required.

In western culture, due to the division between the subjective world and the objective world, a sequence of oppositions come up, such as that between God and man, sensibility and reason, competition between individuals and wars between nations and so on.

\section{(3) A Comparison in Philosophical Base}

The unity as well as harmony between opposite sides is emphasized in Chinese philosophy. However, the differences between sensibility and reason, individuality and generality have been put importance on in western culture. When it comes to ideological approach, Chinese culture seems to be macroscopic and comprehensive with its emphasis on the inner experiences while western culture tends to be more scientific due to its analytical character.

According to the comprehensive character in philosophy, connections and unity among things are emphasized instead of their differences and quantitative analysis, hence resulting in undivided knowledge. Just because of this, Chinese culture seems to be lacking in logic, analytical theories and science despite of its highly developed literary arts and ethical ideology.

However, according to the analytical western philosophy, everything should be divided into two sides. For example, human knowledge should be divided into perpetual knowledge and rational one; the world should be divided into the subjective one and the objective one; the society should be divided into man and God and so on. Due to their emphasis on differences among things, quantitative analysis is widely used to give definite limitations to concepts and categories, hence resulting in clear knowledge. In this way, the precise scientific approach established in the western philosophy has laid the ground work for the scientific development of western arts.

\section{References}

Liu, Wanming. (2001). Chinese Painting Theories. Tianjin Ancient Books Publishing House. (269).

Wang, Liu. (1984). On Art Characteristics. Culture and Arts Press. (1-5).

Wang, Songhua. Shen, Naiquan. Li, Fengchen. Wu, Zhaoshuang. Zhang, Jinhua. Xu, Xuelan. (2000). Philosophy and Art. Tianjin Social Science Institute Press. (1-12). 